\title{
Effects of Kuan-Sin-Yin decoction on immunomodulation and tumorigenesis in mouse tumor models
}

\author{
Tsai-Feng Li ${ }^{1}$, Ching-Cheng Lin ${ }^{1}$, Hui-ping Tsai ${ }^{2}$, Chung-Hua Hsu ${ }^{1 *}$ and Shu-Ling Fu ${ }^{1 *}$
}

\begin{abstract}
Background: Complementary therapies are widely used among cancer patients. Kuan-Sin-Yin (KSY) decoction, a popular qi-promoting herbal medicine, was constituted with several herbs known to exhibit immunomodulating or anticancer activity. After combining these herbs as a compound formula, it is necessary to reassess the immunomodulation effects, the effects on tumor growth, and possible toxicity of KSY.

Methods: The anti-cancer effects of KSY in vivo were determined by measuring the tumor volumes, anticancerassociated cytokines (IFN-gamma, TNF-alpha, IL-2, and IL-12), accumulation of tumor infiltrating leukocytes (TILs), proliferation and apoptosis-related molecular markers (Ki-67, p53, p21, activated caspase 3, and cleaved PARP), and an in situ TUNEL assay. The body weight and serum chemistry of treated mice were also assessed. In vitro, the effects of KSY were evaluated using MTT assay, BrdU incorporation assay and cell growth curve.

Results: In vivo, KSY suppressed bladder or lung cancer growth but did not promote the production of cytokines nor increase the accumulation of TILs. The expression of p53 and p21 in KSY-treated mice were increased. The numbers of apoptotic tumor cells and the expression of apoptosis marker proteins (Caspase 3 and cleaved PARP) were not significantly elevated after KSY treatment. In vitro, the viability and proliferation of tumor cells, but not normal cells, were suppressed by KSY treatment. No significant toxicity was found in KSY-treated mice.

Conclusions: KSY suppressed the tumor growth in vivo and in vitro, which resulted from its cytostatic effects on cancer cells, rather than the induction of anti-cancer immunity. Under these experimental conditions, no apparent toxicity was observed.
\end{abstract}

Keywords: Traditional Chinese medicine, Anti-cancer, Immunomodulation, Cytostatic effect, Kuan-Sin-Yin

\section{Background}

Cancer is the leading cause of death worldwide. Tumor cells have developed a variety of strategies to survive and suppress anti-tumor immune response. The conventional treatments such as surgery, radiotherapy, and chemotherapy impair the patient's immunity [1]. When the immune system is not working well, the frequent infections or chronic inflammation status might contribute to chronic fatigue and tumor progression or recurrence. On the other hand, micrometastases of cancer stem cells frequently lead

\footnotetext{
* Correspondence: owlherbs@yahoo.com.tw; slfu@ym.edu.tw 'Institute of Traditional Medicine, National Yang-Ming University, Taipei 11221, Taiwan

Full list of author information is available at the end of the article
}

to tumor relapse and therapeutic failure after completing the conventional treatment courses [2].

Within the cancer patient population, complementary and alternative medicine (CAM) is used widespread and estimated to be as high as $64 \%$ [3]. It was expected that CAM options could relieve the general illness or undesirable side effects, stimulate and protect immunity, or prevent further tumor progression or recurrence [4-7]. In Taiwan, the use of traditional Chinese medicine (TCM) has been reimbursed by the National Health Insurance since 1996. More than $60 \%$ of outpatients obtained from the National Health Insurance database (NHIRD) had used TCM from 1996-2001 [8]. TCM is very popular in Taiwan, including fighting the related symptoms of malignant neoplasm. 
A compound herbal formula, Kuan-Sin-Yin (KSY) decoction had been used to "reinforce the healthy qi" in traditional Chinese medicine (TCM) theory and it was widely used to treat the dysfunctional gastrointestinal symptoms and chronic fatigue syndrome. In clinical trial study, KSY improved the score on the physical component of the World Health Organization Quality of Life-Brief Version (WHOQOL-BREF) of hepatitis B virus carriers [9]. Individual purified compounds and herbal extracts in KSY have been previously demonstrated to exhibit immunomodulatory or anti-cancer effects in vivo and in vitro [10-19]. Astragalus membranaceus and Codonopsis pilosula, which are ingredients of KSY, were reported that they could function as adjuvant therapies during chemotherapy and radiation therapy in clinical trials [1,20-22].

Current observations indicate that KSY might function as an immunomodulator to suppress tumor growth and as a complementary cancer therapy. However, as a compound formula, these expected therapeutic effects of KSY are rarely studied. In this study, the effects of KSY on immunomodulation and tumorigenesis, as well its toxicity profile were examined in mouse tumor models.

\section{Methods}

\section{Chemicals and reagents}

3-(4,5-Dimethylthiazol-2-yl)-2,5-diphenyltetrazolium bromide (MTT), lipopolysaccharide (LPS), phytohemagglutinin (PHA), 4;6-diamidino-2-phenylindole (DAPI), 5-bromo-2'deoxyuridine (BrdU) were purchased from Sigma Chemical Co. (St. Louis, USA). Lipo-Dox (doxorubicin hydrochloride) was purchased from TTY Biopharm Co. (Taipei, Taiwan); OK-432 (Picibanil) was acquired from Chugai Pharmaceutical (Tokyo, Japan).

\section{Preparation of KSY}

To prepare the KSY, concentrated aqueous extracts of seven Chinese herbs were mixed in fixed ratios (shown in Table 1) and boiled in $500 \mathrm{ml}$ sterile water for 30 minutes. The aqueous extracts of the raw ingredients of KSY were

\section{Table 1 Ingredients in KSY}

\begin{tabular}{lll}
\hline Medicinal plants & Portions used & Ratio \\
\hline Dan Shen & $\begin{array}{l}\text { Dried roots of Codonopsis pilosula (Franch.) } \\
\text { Nannf. }\end{array}$ & 2 \\
Fu Ling & $\begin{array}{l}\text { Dried sclerotium ofthe fungus, Poria cocos } \\
\text { (Schw.) Wolf }\end{array}$ & 2 \\
Bai Zhu & Rhizome of Atractylodes macrocephala Koidez. & 2 \\
Gan Cao & $\begin{array}{l}\text { Dried roots and rhizome of Glycyrrhiza } \\
\text { uralensis Fisch. }\end{array}$ & 1 \\
Nu Zhen Zi & $\begin{array}{l}\text { Dried fruits of Ligustrum lucidum Ait. } \\
\text { Huang Qi }\end{array}$ & $\begin{array}{l}\text { Dried roots of Astragalus membranaceus } \\
\text { (Fisch.) Bunge. }\end{array}$ \\
Guan huo xiang & $\begin{array}{l}\text { Dried branches and leaves of Pogostemon } \\
\text { cablin (Blanco) Bench. }\end{array}$ & 2 \\
\hline
\end{tabular}

provided by the manufacturer, Sun-Ten Pharmaceutical Co. Ltd. (Taipei, Taiwan). The amounts of heavy metals, residual pesticides and microbes in each herb were inspected and met the safety criteria of Taiwan Food and Drug Administration (TFDA). The final concentration was defined as the weight of the aqueous herbal mixtures $(152.3 \mathrm{~g})$ in $500 \mathrm{ml}$ of $\mathrm{ddH}_{2} \mathrm{O}$, which was approximately $0.3 \mathrm{~g} / \mathrm{ml}$. For in vitro experiments, a quantified amount $(15 \mathrm{ml})$ of the KSY extract was processed with a freezedryer to obtain crystal powder $(0.87 \mathrm{~g})$, which was then redissolved in sterile $\mathrm{ddH}_{2} \mathrm{O}$, filtered and stored as a stock solution $(100 \mathrm{mg} / \mathrm{ml})$ at $-20^{\circ} \mathrm{C}$. The protocol regarding HPLC analysis of KSY was described in the supplementary section "Additional file 1".

\section{Cell lines and culture conditions}

The mouse bladder carcinoma cell line MBT-2 (obtained from Dr. Lih-Hwa Hwang, National Yang-Ming University, Taiwan), the mouse Lewis lung carcinoma line LLC1 (American Type Culture Collection; Manassas, USA) and the primary mouse embryo fibroblast MEF cell line (obtained from Dr. Ting-Feng Tsai, National Yang-Ming University, Taiwan) were cultured in Dulbecco's modified Eagle medium (Invitrogen, CA, USA) supplemented with $10 \%$ heat-inactivated fetal bovine serum (FBS), 100 units $/ \mathrm{ml}$ penicillin, $100 \mu \mathrm{g} / \mathrm{ml}$ streptomycin and $2 \mu \mathrm{M}$ L-glutamine in a humidified $5 \% \mathrm{CO}_{2}$ incubator at $37^{\circ} \mathrm{C}$.

\section{Animals}

C3H/HeN, BALB/cAnN-Foxn1nu/Cr1Nar1, and C57BL/ 6 mice were purchased from the National Laboratory Animal Center (Taipei, Taiwan) and maintained at the Animal Center of Yang-Ming University (Taipei, Taiwan) following the Guidelines for the Care and Use of Laboratory Animals (National Institutes of Health, USA). All experiments utilizing mice were approved by the Institutional Animal Care and Use Committee (IACUC Approval No. 1001246) at National Yang-Ming University (Taipei, Taiwan).

\section{Mouse tumor models and treatment protocols}

Treatment protocols in three different mouse tumor models were used in this study, which are outlined in Figure 1 . In all models, cancer cells $\left(1 \times 10^{6}\right)$ were injected s.c. into the dorsum of mice. The tumor volume $(V)$ was calculated by the following formula: $V=1 / 2\left(L \times W^{2}\right)$, where $L$ is the length and $W$ is the width of tumor. After tumor volumes reached $100 \pm 20 \mathrm{~mm}^{3}$ ( 10 days), mice were randomly assigned into different drug treatment groups (Figure 1, day 0).

For the bladder tumor model in immunocompetent mice (Figure 1, C3-B), MBT-2 bladder cancer cells were inoculated into $\mathrm{C} 3 \mathrm{H} / \mathrm{HeN}$ mice, and the mice were randomly divided into three different treatment groups: the 


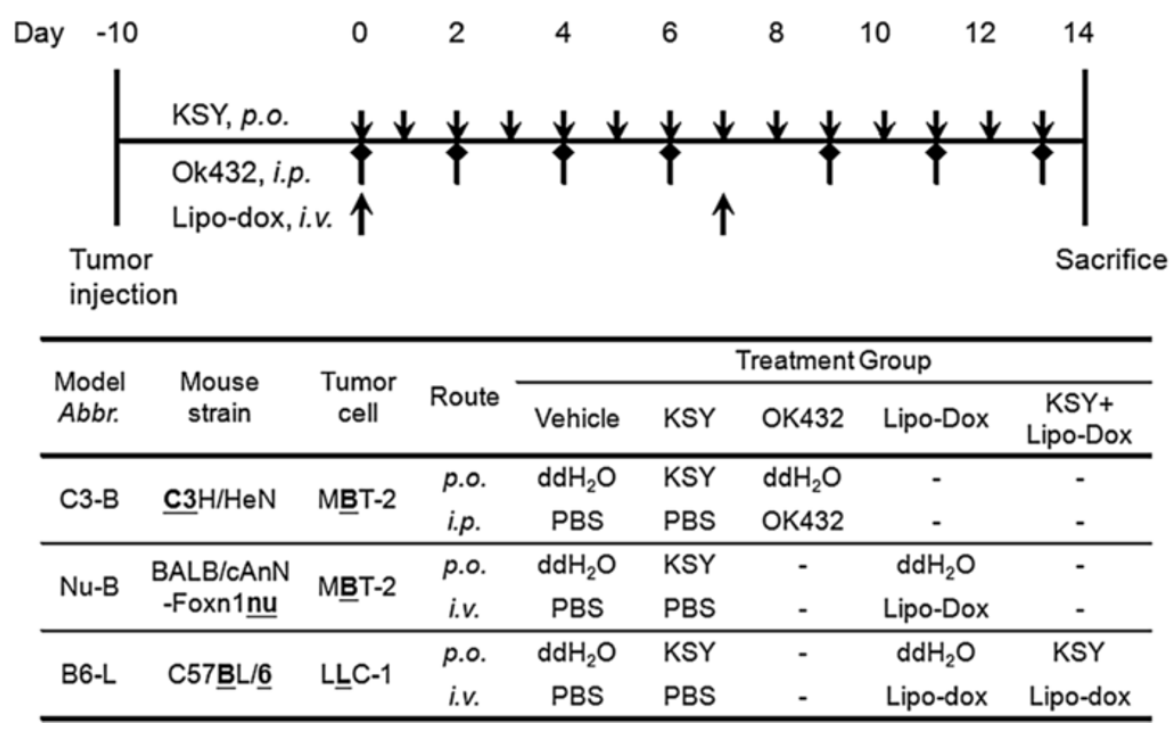

Figure 1 Outline of tumor models and treatment protocols used in this study. (Upper panel) treatment protocols and administration routes for different drugs. KSY: 1000 mg/kg/day, p.o.; OK-432: 4 mg/kg per injection, i.p.; Lipo-Dox: 1.5 mg/kg per injection, i.v.. (Bottom panel) tumor mouse models used in this study. In the C3-B model, $\mathrm{C} 3 \mathrm{H} / \mathrm{HeN}$ mice were injected with a syngeneic bladder cancer cell line MBT-2. In the Nu-B model, BALB/CAnN-Foxn1nu/Cr1Nar1 mice were inoculated with MBT-2 cells. In the B6-L model, C57BL/6 mice were injected with a syngeneic lung cancer cell line LLC-1. The detailed experimental procedures are described in the "Methods".

KSY-treated group, the vehicle group and the OK432treated group. OK432 is a Streptococcal immunotherapeutic agent used as the positive control. The KSY-treated group received KSY treatments (1000 mg/kg/day, p.o.). The OK432-treated group received OK-432 treatments (4 mg/kg, i.p.) on days $0,2,4,6,9$, and 12 .

For the bladder tumor model in immunocompromised mice (Figure 1, Nu-B), the nude mouse strain BALB/ cAnN-Foxn1nu/Cr1Nar1 were inoculated with MBT-2 bladder cancer cells and divided into three treatment groups: the KSY-treated group, the vehicle group and the liposome-doxorubicin (Lipo-Dox)-treated group. The cytotoxic chemotherapeutic drug liposome-doxorubicin was used as the positive control. The KSY-treated group received KSY (1000 mg/kg/day, p.o.). For the LipoDox-treated group, the tumor-bearing mice were injected with Lipo-Dox (1.5 mg/kg in PBS i.v.) on days 0 and 7.

The vehicles for the KSY, OK-432, and Lipo-Dox groups were $\mathrm{ddH}_{2} \mathrm{O}, \mathrm{PBS}$, and $\mathrm{PBS}$, respectively. The KSY dosage used in this study was referred from that used in clinical study described previously [9].

For the lung cancer model (Figure 1, B6-L) in immunocompetent mice, LLC-1 lung cancer cells were inoculated into the syngeneic C57BL/6 mouse strain. The experimental treatment protocol was similar to the $\mathrm{Nu}-\mathrm{B}$ model protocol described above. For the co-treatment group combining KSY with Lipo-Dox, tumor-bearing mice were injected Lipo-Dox (1.5 mg/kg in PBS) i.v. on day 0 and 7 , and at the same time, they were given KSY $(1000 \mathrm{mg} / \mathrm{kg} /$ day) p.o. daily.

\section{Cytokine production measurements}

The tumor tissues were lysed with protein extraction buffer (50 mM Tris- $\mathrm{HCl}, \mathrm{pH}$ 7.4, $15 \mathrm{mM} \mathrm{NaOH}, 0.1 \%$ NP-40, $5 \mathrm{mM}$ EDTA, and $10 \mathrm{mM}$ EGTA) containing protease inhibitors (Sigma-Aldrich). The concentrations of cytokines in the tumor lysates $(500 \mu \mathrm{g})$ were measured by ELISA kits (R\&D Systems, Minneapolis, USA). Primary splenocytes were isolated from the treated mice as previously described [23], and then $3 \times 10^{6}$ splenocytes from each treated mouse were cultured and stimulated with the T cell mitogen PHA for $72 \mathrm{~h}$. Afterwards, the supernatants from the splenocytes were collected to measure the cytokine concentrations.

\section{Splenocyte-conditioned medium (SCM)-mediated cytotoxicity assay}

The splenocytes $\left(1.5 \times 10^{7}\right)$ were cultured for $48 \mathrm{~h}$ with PHA and the culture medium was collected as splenocyteconditioned medium (SCM). Next, MBT-2 cells $\left(2 \times 10^{5}\right)$ were incubated with the SCM for an additional $48 \mathrm{~h}$. The SCM-mediated cytotoxicity of MBT-2 cells was measured as previously described using propidium iodide (PI, 20 $\mu \mathrm{g} / \mathrm{ml}$ ) and a FACS Calibur flow cytometer (BD Biosciences, NJ, USA) [24].

\section{Quantitative Reverse Transcription Polymerase Chain Reaction (qRT-PCR)}

The protocols for isolation of total RNA from tumor tissues and synthesis of cDNAs have been previously described [24]. The primer sequences used in this study 
are summarized in Additional file 2: Table S1). The GAPDH mRNA level was used as the internal control. All PCR reactions were performed using an Applied Biosystems model 7000 instrument (Applied Biosystems, California, USA).

\section{TUNEL assay}

The apoptotic cells in paraffin-embedded tumor sections were detected with an in situ cell death detection kit based on the labeling of DNA strand breaks (Roche Diagnostics, Mannheim, Germany). The tumor sections were counterstained with DAPI and analyzed by fluorescence microscopy (Olympus BX61, Tokyo, Japan). The image processing and analysis were carried out using the MetaMorph ${ }^{\oplus}$ Software (Molecular Devices, Inc., California, USA).

\section{Immunohistochemistry}

Paraffin-embedded tumor sections $(3 \mu \mathrm{m})$ were soaked in an antigen retrieval buffer containing $10 \mathrm{mM}$ sodium citrate ( $\mathrm{pH}$ 6.0) and treated twice with microwave irradiation $(650 \mathrm{~W})$ for $10 \mathrm{~min}$. An antibody against Ki-67 (BD, California, USA) was incubated with the tumor sections overnight. After washing with PBS, the tumor sections were incubated with biotinylated secondary antibodies and an avidin/streptavidin-based detection system (Vectastain ${ }^{\odot}$ Elite $^{\ominus}$ ABC peroxidase kit, Vector laboratories, lnc., Burlingame, USA), followed by treatment with a 3, 3'-diaminobenzidine tetrahydrochloride (DAB) staining system (Merck Millipore, Billerica, MA, USA) and counterstaining with hematoxylin. The stained sections were imaged using a microscope (Olympus BX61, Tokyo, Japan).

\section{Immunoblotting}

The tumor tissues were lysed with a protein extraction buffer containing protease inhibitors. Protein lysate $(50 \mu \mathrm{g})$ from each sample was assessed for the expression of $\mathrm{p} 53$, p21, Caspase-3, PARP or GAPDH as previously described [25]. Band intensities were quantified using the Image J program, version 1.40 (NIH, Bethesda, USA).

\section{MTT assays}

To measure cell viability, MBT-2 $\left(3 \times 10^{3}\right)$, LLC-1 $\left(1 \times 10^{3}\right)$ and $\operatorname{MEF}\left(3 \times 10^{3}\right)$ cells were cultured in 96-well plates overnight, treated with the vehicle (sterile $\mathrm{ddH}_{2} \mathrm{O}$ ), KSY extract, or doxorubicin for 24,48 , and $72 \mathrm{~h}$. Cellular metabolic activity was measured by MTT-based colorimetric assays as previously described [26].

\section{Growth curve and BrdU incorporation assay}

To establish a growth curve, MBT- 2 cells $\left(1 \times 10^{5}\right)$ were cultured overnight and treated with vehicle (sterile $\mathrm{ddH}_{2} \mathrm{O}$ ), KSY, or lipo-dox for 24, 48, and $72 \mathrm{~h}$. Adherent and floating cells were both collected, and the number of viable cells was counted by trypan blue dye exclusion. For BrdU incorporation assays, MBT-2 cells $\left(1 \times 10^{5}\right)$ were cultured overnight and synchronized by $24 \mathrm{~h}$ of growth in serum-free medium. The serum-starved cells were incubated with vehicle or drugs for 22 and $46 \mathrm{~h}$ and treated with $10 \mathrm{mM}$ BrdU for $2 \mathrm{~h}$, and then both the adherent and floating cells were collected. The harvested cells were fixed in $4 \%(\mathrm{w} / \mathrm{v})$ buffered-formaldehyde in PBS, permeabilized with $0.5 \%$ Triton $\mathrm{X}-100$ in PBS, and treated with DNase I. After incubating with an antiBrdU antibody (BD, California, USA) and a fluoresceinconjugated secondary antibody (Jackson ImmunoResearch Laboratories, Inc., PA, USA), the cells were treated with RNase $(20 \mu \mathrm{g} / \mathrm{ml})$, stained with PI $(20 \mu \mathrm{g} / \mathrm{ml})$, and then analyzed by flow cytometry.

\section{Blood chemistry measurements}

Blood samples were collected from mice under terminal anesthesia through cardiac punctures. Clear serum samples were prepared and measured with a Fuji Dri-Chem Clinical Chemistry Analyzer FDC 3500 (Norsted, Germany).

\section{Statistical analysis}

All data are presented as the mean \pm SEM (standard error of mean) and are from at least three independent experiments. The Mann-Whitney $U$ test was used to determine the significance of the between-group differences. Statistical significance was set at $p<0.05$. All $p$ values were two-tailed, and all statistical analyses were performed with the SPSS statistics software (Statistical Product and Service Solutions, IBM, New York, USA).

\section{Results}

The KSY dosage used in animal experiments is referred to the clinical dose for human subjects [9]. The human dosage of KSY was translated to mouse dosage $(\sim 1500 \mathrm{mg} / \mathrm{kg})$ using a formula described previously [27]. After preliminary toxicity/efficacy experiments, the dosage of $1000 \mathrm{mg} / \mathrm{kg}$ was chosen for subsequent in vivo experiments.

\section{The HPLC analysis of KSY}

The HPLC chromatogram of KSY was shown in Additional file 3: Figure S1 and marker compounds (glycyrrhizic acid, liquiritin, liquiritin apioside, and calycosin-7-O- $\beta$ D-glucoside) were well resolved by gradient elution. Analysis showed that $1 \mathrm{~g}$ KSY contained $29.59 \pm 0.78 \mu \mathrm{g}$ of calycosin-7-O- $\beta$-D-glucoside, $187.08 \pm 4.28 \mu \mathrm{g}$ of liquiritin apioside, $228.42 \pm 2.91 \mu \mathrm{g}$ of liquiritin, and $701.19 \pm$ $7.92 \mu \mathrm{g}$ of glycyrrhizic acid. 
KSY delays tumor growth in immunocompetent and immunocompromised mice

To investigate the effect of KSY treatment on tumor development, the growth of the MBT-2 bladder cancer cells in immunocompetent and immunocompromised hosts (Figure 1, C3-B and $\mathrm{Nu}-\mathrm{B}$, respectively) was examined. The tumor volumes of the KSY- and OK432treated mice were reduced compared with the vehicle group in the C3-B model (Figure 2a). Similar suppressive effects were observed in the KSY- and Lipo-Dox-treated groups in the $\mathrm{Nu}-\mathrm{B}$ model (Figure 2b).

\section{KSY does not induce anticancer immunity}

In the $\mathrm{C} 3-\mathrm{B}$ mouse model, the expression of the anticancer-associated cytokines (TNF- $\alpha$, IFN- $\gamma$, IL-2, and IL-12) were measured by ELISA assay in the host spleen and the local tumor area. The result showed that KSY did not increase the expression of these cytokines in the tumor area, as compared with the vehicle treatment (Figure 3a). Furthermore, the cytokine levels secreted from splenocytes isolated from KSY-treated mice, in the presence of PHA, were similar to that in vehicle groups (Figure $3 \mathrm{~b}$ ). Conversely, the TNF- $\alpha$, IFN- $\gamma$ and IL-12 secretions were increased in splenocytes of the OK-432 group (Figure 3b). The SCM-driven cytotoxicity of MBT-2 cells correlated with splenocyte cytokine expression, as the SCM-mediated cytotoxicity was significantly enhanced in the OK-432 group but not in the KSY group (Figure 3c).

The histological examination was next performed. The tumor-infiltrating leukocytes were significantly elevated in the tumors of OK-432-treated mice, but not in the KSY group and vehicle group (Figure $3 \mathrm{~d}$ ). Consequently, the amounts of tumor-infiltrating leukocytes after KSY treatment were determined by measuring of the mRNA expression levels of various immune cell markers. KSY treatment did not promote the recruitment of immune cells (i.e., $\mathrm{CD}^{+}{ }^{+} \mathrm{T}$ cells, $\mathrm{CD}^{+} \mathrm{T}$ cells, dendritic cells, NK cells and macrophages) at tumor sites, but Ok-432 indeed elevated local immune cells (Figure 3e).

KSY treatment reduces proliferation of cancer cell in vivo The Ki-67 expression was measured by IHC in the tumor tissues in Nu-B mouse model. As shown in Figure 4a, the Ki-67 expression was significantly lower in both the LipoDox- and KSY-treated groups compared with the vehicle group. Furthermore, the expression levels of cell cycle regulators, p53 and p21, in tumor tissues were elevated in the KSY group. The p53 expression of Lipo-Dox group was increased compared with the vehicle group (Figure 4b).

\section{KSY treatment does not increase tumor cell apoptosis} in situ

The apoptotic tumor cells were visualized by an in situ TUNEL assay. KSY treatment did not enhance the tumor cell apoptosis (Figure 5a), and this observation was confirmed by the expression patterns of activated caspase 3 and cleaved PARP in the tumor tissues (Figure 5b).

\section{In vitro KSY treatment causes cytotoxicity on cancer cells} but not on normal cells

The cancer cell viability was examined by an MTT assay in vitro. As shown in Figure 6a, the KSY treatments reduced the viability of MBT-2 tumor cells in a concentration- and time-dependent manner. Under the same experimental conditions, KSY treatments did not cause significant cytotoxicity on primary mouse embryonic fibroblasts (MEFs), but doxorubicin treatment reduced MEF viability (Figure 6b).

\section{In vitro KSY treatment suppresses the proliferation of MBT-2 cells}

As shown in Figure 6c, KSY treatment at $1500 \mu \mathrm{g} / \mathrm{ml}$ or $2000 \mu \mathrm{g} / \mathrm{ml}$ for $72 \mathrm{~h}$ significantly suppressed the proliferation of MBT-2 cells in a concentration-dependent manner. The DNA synthesis ability was further analyzed by BrdU/ (a)

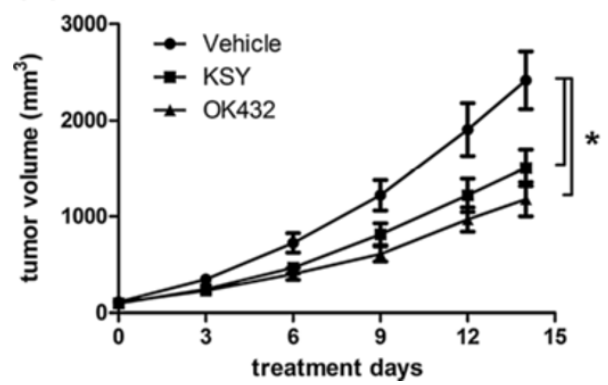

(b)

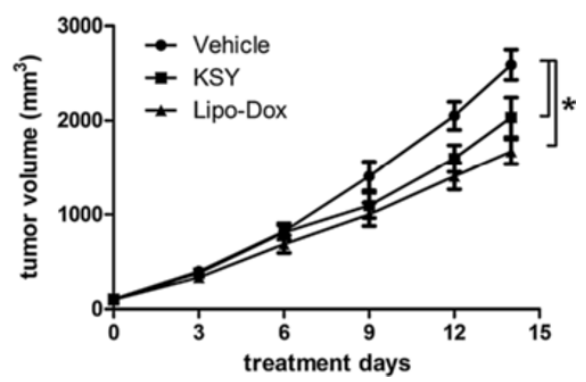

Figure 2 KSY delays tumor growth in both immunocompetent and immunocompromised mice. The MBT- 2 cancer cells $\left(1 \times 10^{6}\right)$ were injected s.c. into the dorsum of mice. After 10 days, tumor-bearing mice were randomly grouped and treated with vehicle or indicated drugs using the treatment protocol described in Figure 1. The mean tumor volumes of treated mice on the indicated days are shown. (a) The C3-B model ( $n=17-20$ for each group); (b) The Nu-B model ( $n=14$ for each group). *indicates $p<0.05$ versus the vehicle group. 


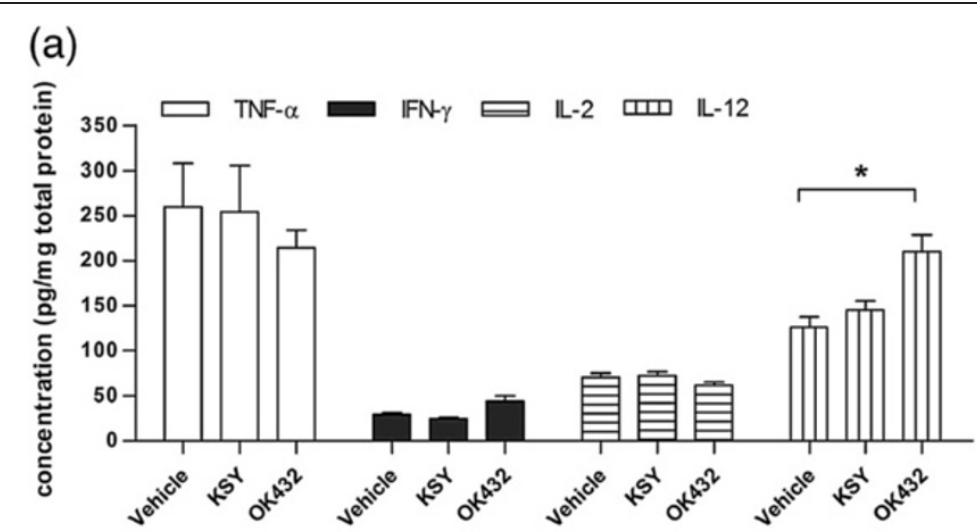

(b)

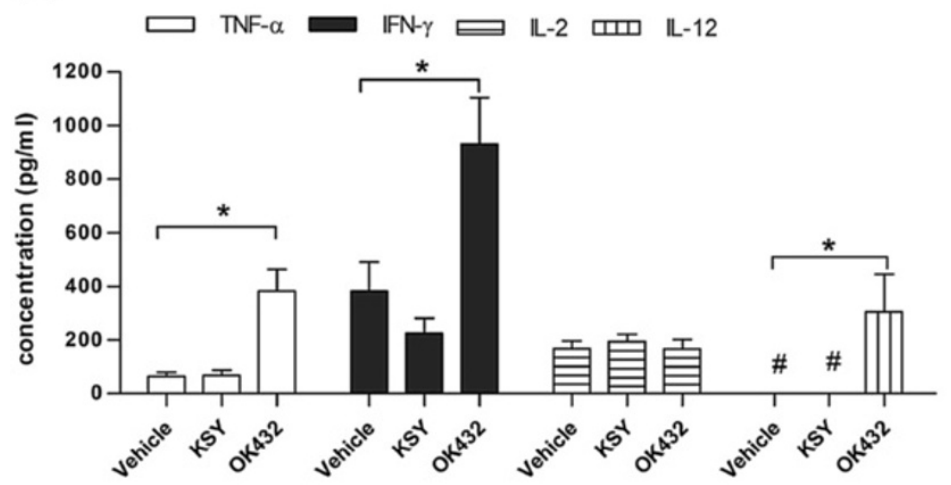

(c)

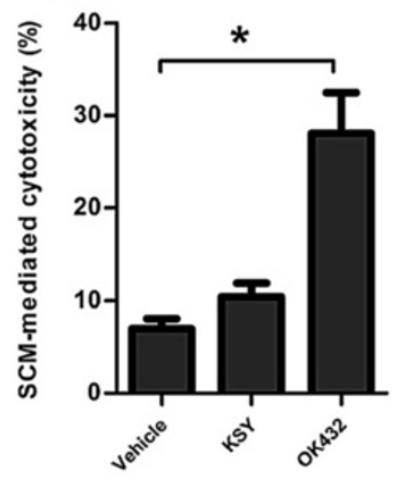

(d)

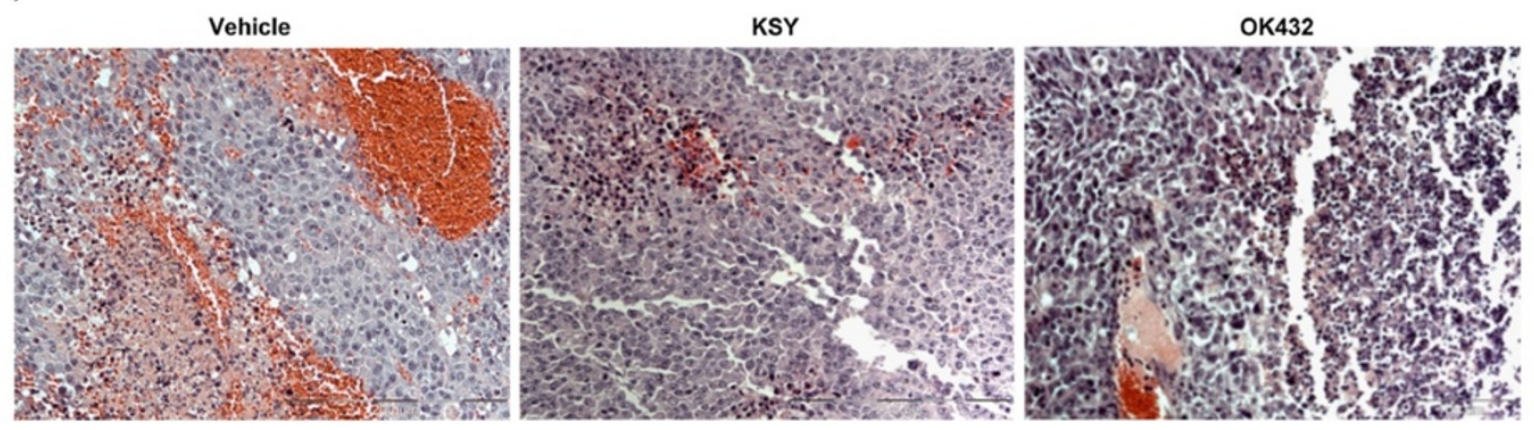

(e)
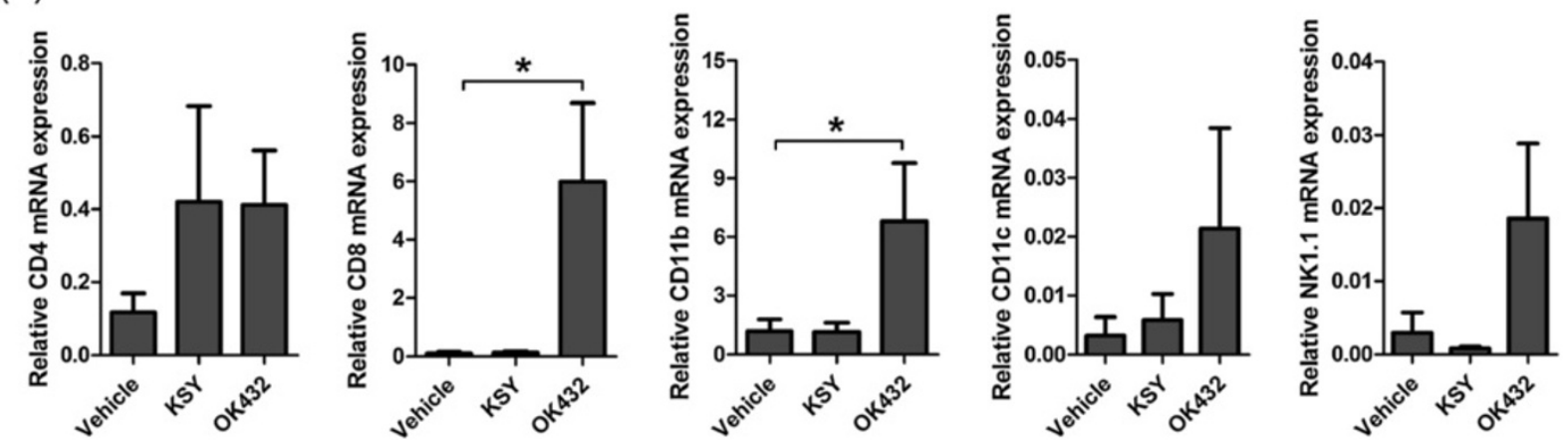

Figure 3 (See legend on next page.) 
(See figure on previous page.)

Figure $3 \mathrm{KSY}$ neither enhances the secretion of anticancer-associated cytokines, nor increases the recruitment of tumor-infiltrating leukocytes in tumor-bearing mice. The anticancer immunity in the bladder cancer model (C3-B model in Figure 1) was evaluated. (a) The expressions of indicated cytokines in tumor tissues were measured by ELISA. (b) The splenocytes $\left(3 \times 10^{6} / \mathrm{ml}\right)$ from each treatment group were cultured in the presence of PHA (5 $\mathrm{\mu g} / \mathrm{ml})$ for $72 \mathrm{~h}$, and the amount of cytokines in the culture medium were measured by ELISA. (c) The culture medium collected from the splenocytes of drug-treated mice (splenocyte-conditioned medium; SCM) was incubated with MBT-2 cells for $48 \mathrm{~h}$. The death of MBT-2 cells was detected by PI stain and analyzed by flow cytometry. \# indicates undetectable. *indicates $p<0.05$ versus the vehicle group. $n=18-21$. (d) Tumor tissues from each treatment group in C3-B model were fixed, sectioned and stained with hematoxylin and eosin (H\&E stain) for microscopic examination. (e) The expression of various immune cell maker genes in tumor tissues of C3-B model mice was measured using qRT-PCR. CD4: T helper cells; CD8: cytotoxic T cells; CD1 1b: macrophages; CD11c: dendritic cells; NK1.1: NK cells. Three independent experiments were performed ( $n=3$ for each group). *indicates $p<0.05$ versus the vehicle group.

PI staining and flow cytometry. For MBT-2 cells subjected to a 24-h KSY treatment, the percentage of BrdU-positive cells (S phase) was significantly reduced (Figure 6d). This reduction of S-phase cells was more evident after longer treatment $(48 \mathrm{~h})$ with higher concentrations of KSY (1500 or $2000 \mu \mathrm{g} / \mathrm{ml}$ ) (Additional file 4: Figure S2).

\section{The toxicity assessment of in vivo KSY treatment in} immunocompetent tumor-bearing mice

The body weight, hepatic and renal function were measured in C3-B model. The serum levels of alanine aminotransferase and aspartate aminotransferase (AST) were measured as an index of hepatic function, and the levels of (a)
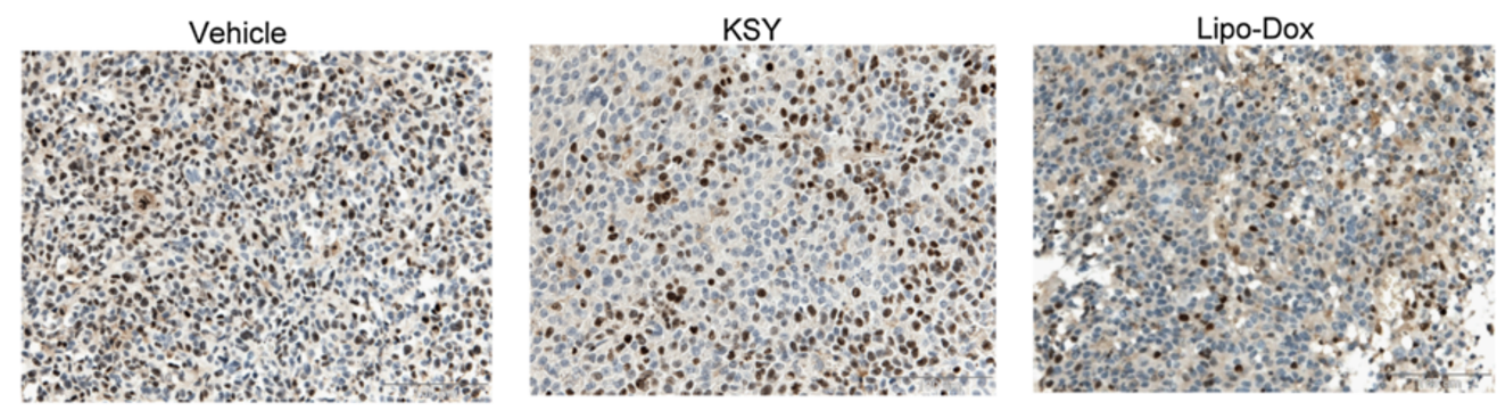

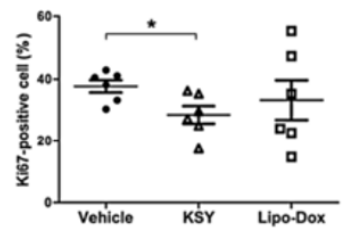

(b)
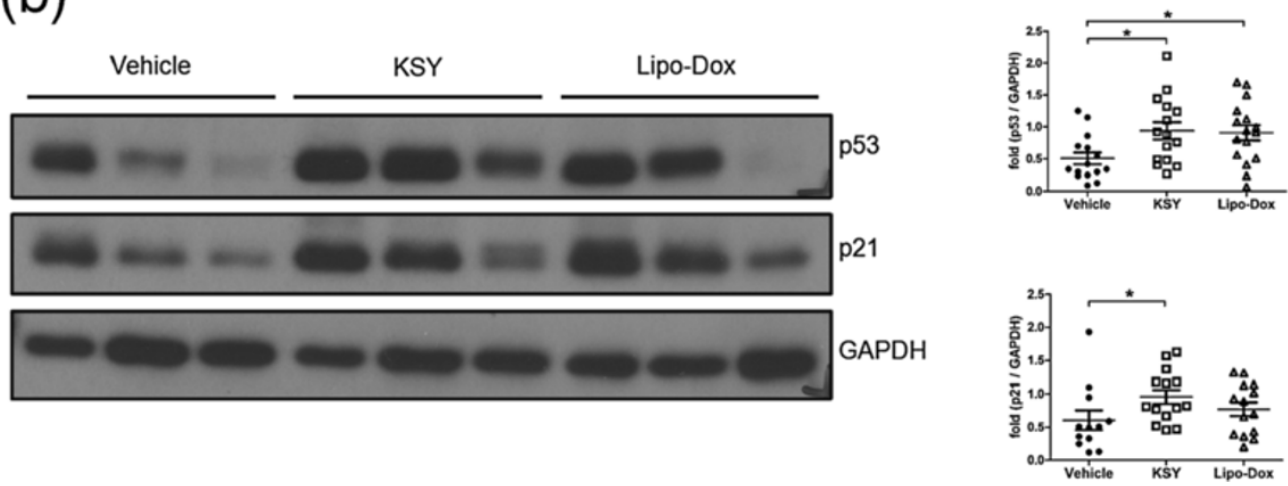

Figure 4 In vivo KSY treatment reduces Ki-67 expression and increases the expression of p53 and p21. (a) In the Nu-B model, Ki-67-positive cells (brown) in tumors were detected by immunohistochemistry. Five fixed fields from each tumor section were analyzed for the number of Ki-67-positive cells. The percentage of Ki-67-positive cells was calculated by the number (Ki-67-positive cells/the total cell number of five fields) $\times 100 \%$. The quantification of the percentage of Ki-67-positive cells is shown in the lower panel. (b) The protein expression levels ofp53 and p21 in tumors of Nu-B model were detected by Western blot. The quantification data are shown in the left panel. *indicates $p<0.05$ versus the vehicle group. 
(a)
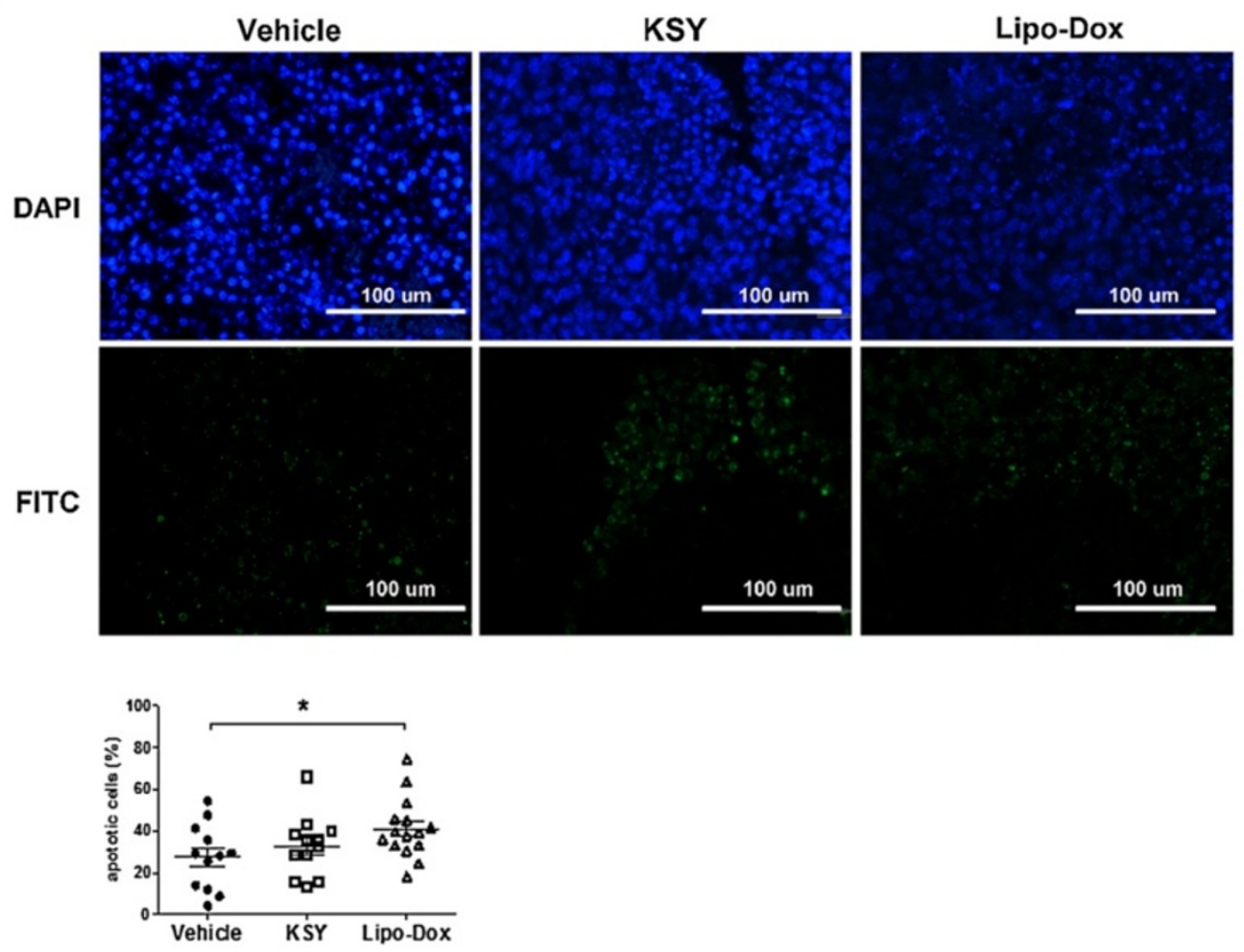

(b)
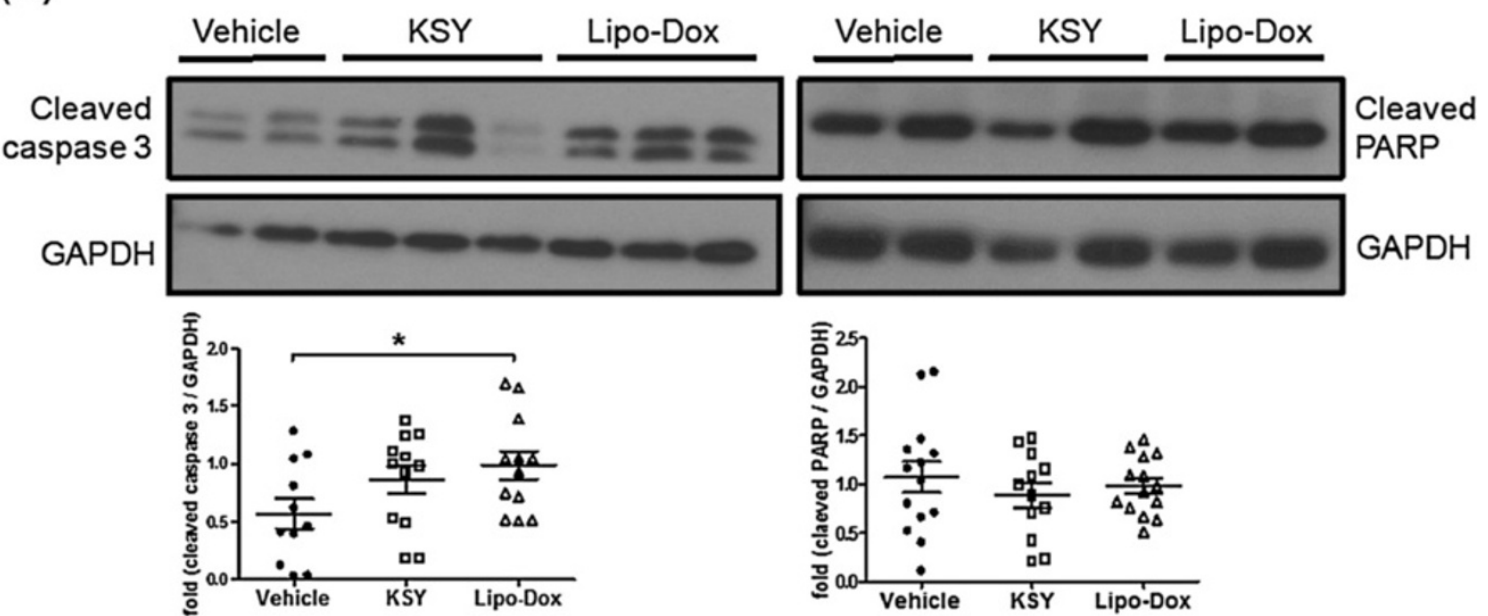

Figure 5 KSY treatment does not increase tumor cell apoptosis. (a) In the Nu-B model, the apoptotic cells (green) were detected by a TUNEL assay. Five independent fields from each tumor tissue section were analyzed for the numbers of TUNEL-positive cells. The percentage of apoptotic cells is shown in the bottom panel and was determined by the following equation: (the number of apoptotic cells/the total cell number of five fields) $\times 100 \%$. (b) In the Nu-B model, the expression levels of active caspase 3 and cleaved PARP in tumor tissues were measured by Western blot. The quantification data are also shown. ${ }^{*}$ indicates $p<0.05$ versus the vehicle group.

blood urea nitrogen (BUN) and creatinine served as an index of renal function. No difference in these parameters was observed between the KSY and control groups, demonstrating the safety of KSY administration in tumor-bearing mice under this treatment protocol (Figure $7 \mathrm{a}$ and $\mathrm{b}$ ).
The therapeutic and toxicity effects of KSY in a lung cancer model

To evaluate whether in vivo KSY treatment could suppress other type of malignant tumor, a syngeneic lung cancer mouse model was used (Figure 1, B6-L model). 


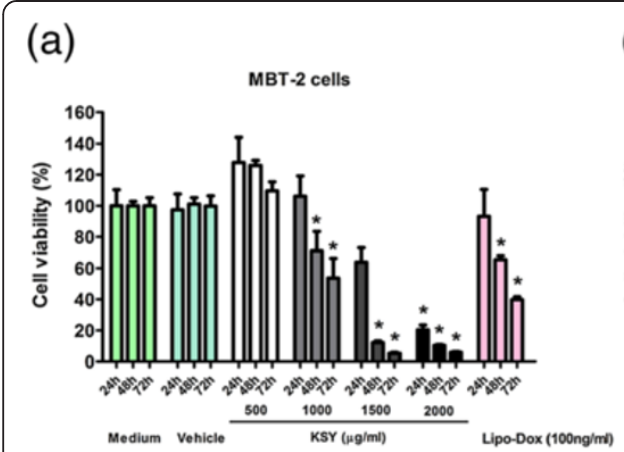

(b)

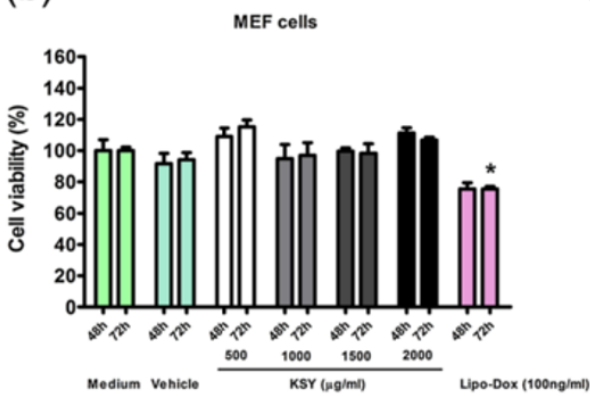

(c)

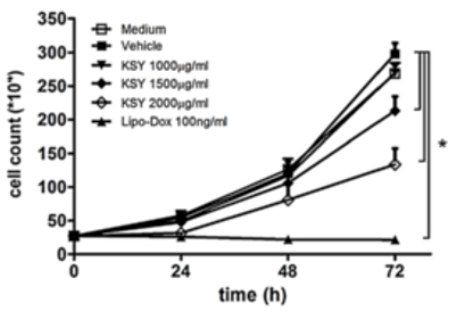

(d)
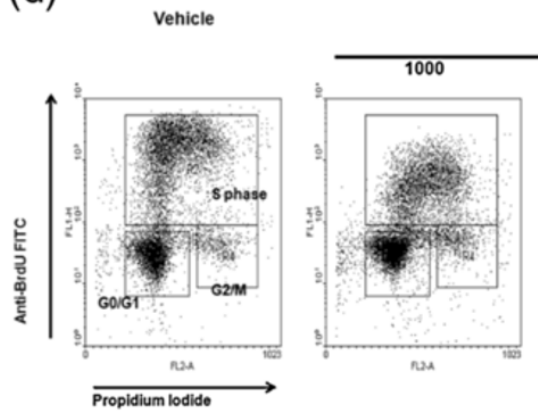

$\mathrm{KsY}(\mu \mathrm{g} / \mathrm{ml})$ Lipo-Dox100ng/ml
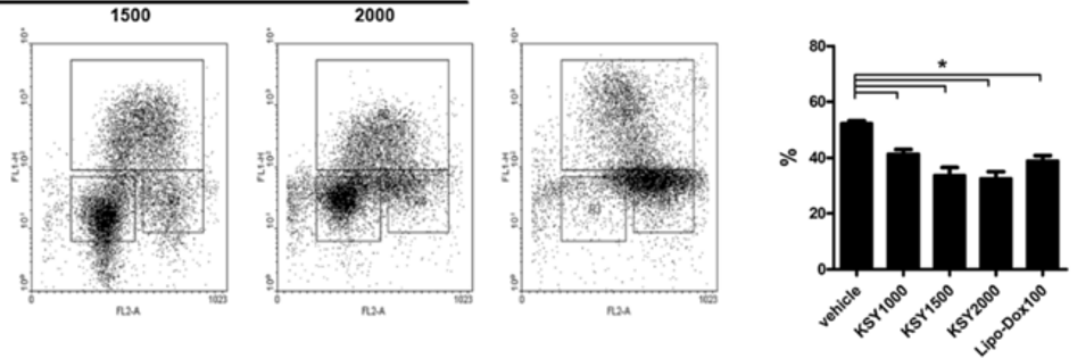

Figure 6 In vitro KSY treatment decreases cancer cell viability, suppresses proliferation, and interferes with cell cycle progression. (a) The viability of MBT-2 cancer cells (3,000 cells/well in a 96-well plate) was determined by an MTT assay after a 24, 48, or 72 h vehicle or drug treatment at indicated concentrations. Doxorubicin (Lipo-Dox) served as the positive control. (b) An MTT assay was also used to measure the viability of primary MEF cells (3,000 cells/well in a 96-well plate). (c) MBT-2 cancer cells $\left(1 \times 10^{5}\right)$ were treated with different concentrations of KSY for 24, 48 or $72 \mathrm{~h}$, and the viable cells were determined using Trypan blue exclusion assays. Doxorubicin (Lipo-Dox) served as the positive control. (d) MBT-2 cells $\left(1 \times 10^{5}\right)$ were treated with different concentrations of KSY for $24 \mathrm{~h}$ and then analyzed with BrdU/PI staining and flow cytometry. Representative FACS dot plots are shown in the left panel, and DNA synthesis (S phase) was determined by quantifying the BrdU-positive cells in the dot plot. Quantification data of BrdU-positive cells are shown in the right panel. *indicates $p<0.05$ versus the vehicle group.

In addition, the combination treatment of KSY and doxorubicin was performed to assess the chemosensitizing effect of KSY. As shown in Figure 8a, the tumor volumes in mice treated with KSY, Lipo-Dox, and co-treatment were significantly reduced compared with the vehicle group, revealing the tumor suppression activity of KSY in this model. However, there was no difference on tumor growth between the combined treatment group and Lipo-Dox group.

The toxicity effects in B6-L model mice were also assessed. Compared to the vehicle group, KSY and cotreatment did not induce significant differences in body weights (Figure $8 \mathrm{~b}$ ) or in the serum levels of AST and creatinine (Figure 8c). These biochemical values were within the normal ranges described in the Mouse Phenome Database [28]. Therefore, KSY treatment along or combination with Lipo-Dox did not induce significant hepatic and renal toxicity in B6-L model mice.

\section{Discussion}

KSY treatment delayed tumor growth in both immunocompetent and immunocompromised tumor-bearing mice (Figure 2), indicating that KSY could impair tumor growth with or without an intact immune system. The tumor-suppressive effects of KSY in immunocompromised hosts further validated that KSY had direct inhibitory effects on tumor cells. In tumor-bearing immunocompetent mice, neither the number of tumor infiltrated lymphocytes nor the anti-cancer cytokines were increased after KSY treatment (Figure 3). Collectively, the data showed that the potential anticancer activity of KSY acted mainly through the suppression of bladder cancer cells rather than the stimulation of anticancer immunity (Figures 2 and 3).

The immune cells in tumor microenvironment have been found to modulate tumor progression [29]. Induction of anticancer immunity is considered as a promising strategy for cancer therapy [30,31]. Several ingredients of KSY have been previously demonstrated to exhibit immunomodulatory activity in pre-clinical studies [10-19]. Conversely, our data showed that KSY did not appear to induce immunity in these models and the anticancer activity of KSY is independent of the immune modulation (Figures 2 and 3). The discrepancy between these observations and previous reports regarding the immunemodulating effects may result from differences in the dosages, the experimental conditions used, the extraction 


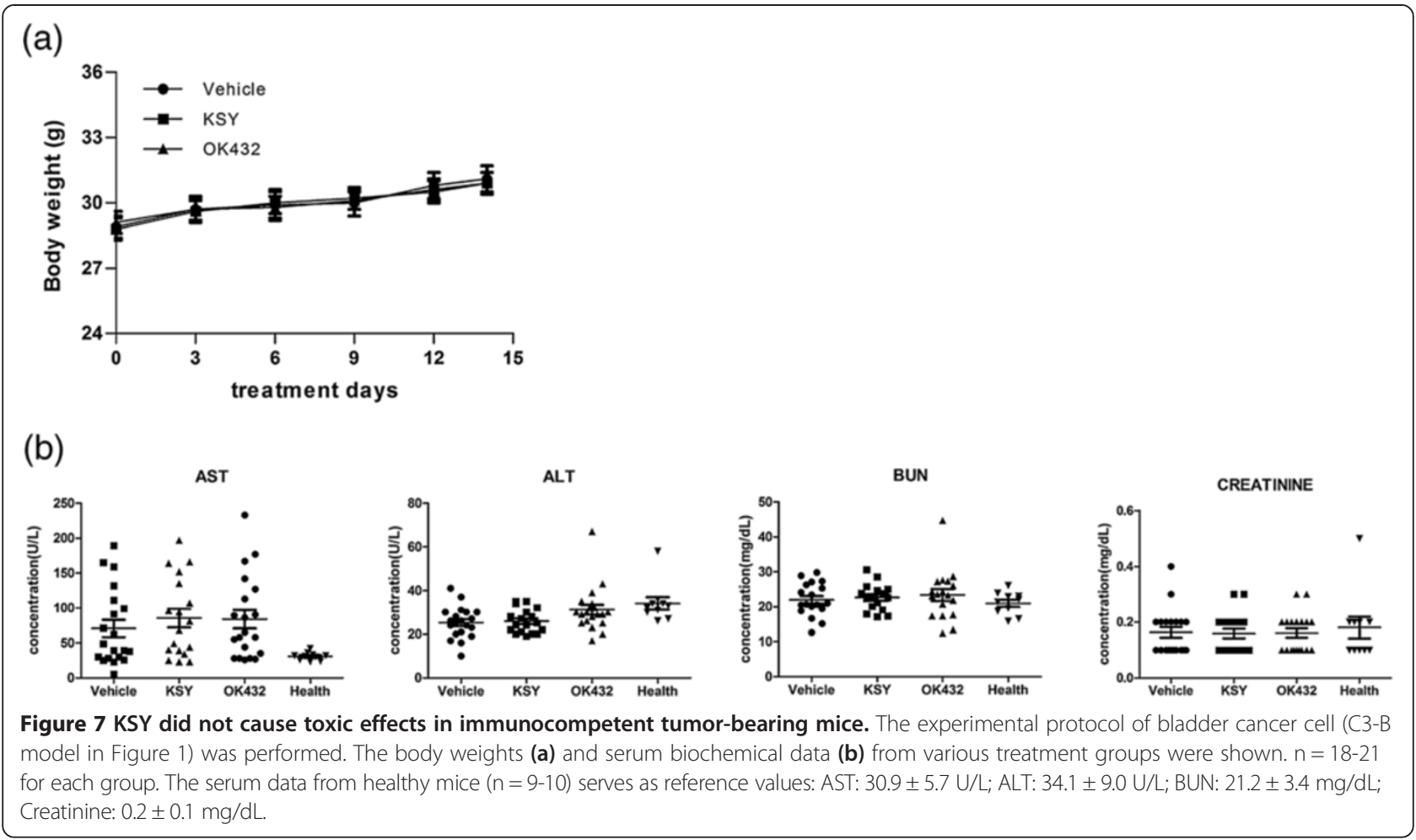

(a)

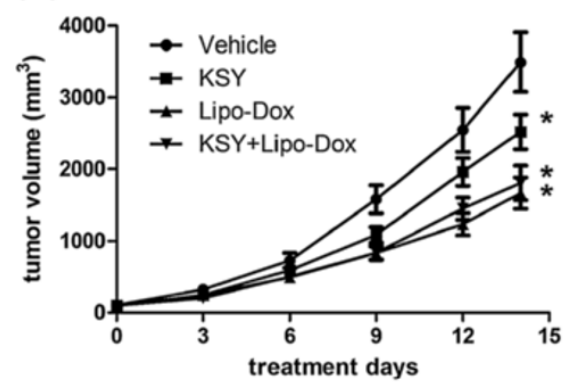

(b)

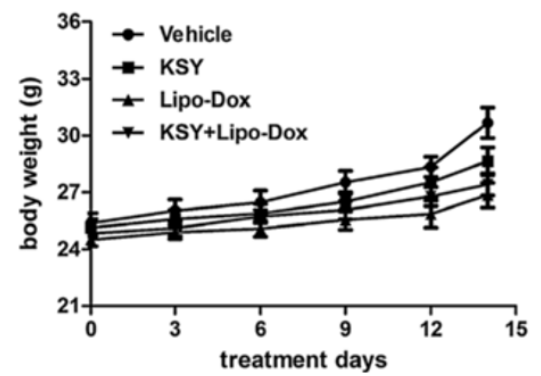

(c)
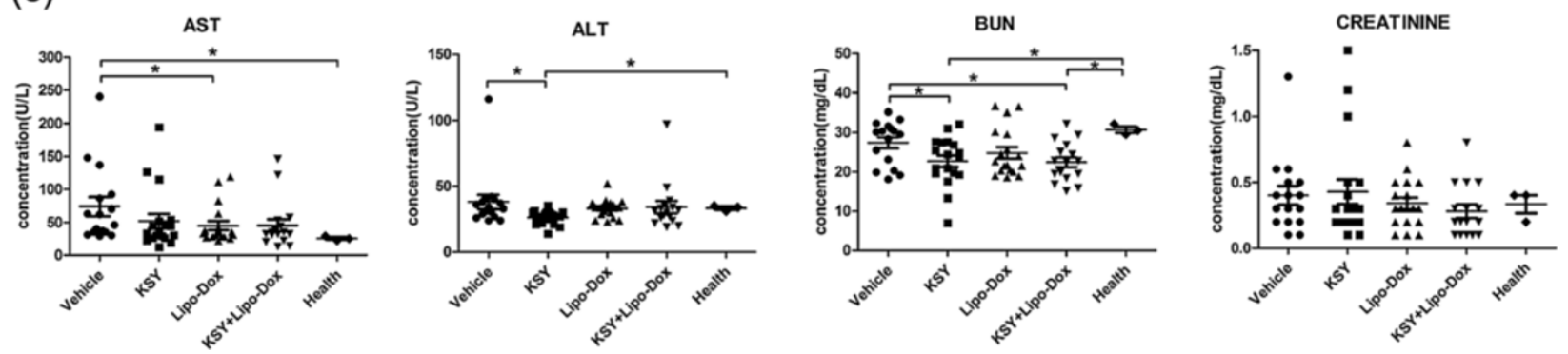

Figure 8 The tumor-suppressive effects and toxicity assessments in a lung cancer model. (a) The experimental protocol of lung cancer model (B6-L model in Figure 1) was performed and the tumor volumes were measured ( $n=15-17$ for each treatment group). (b) The body weights from all treatment groups are shown. (c) The serum biochemical data, from treatment groups or from healthy mice, were measured. The serum data from healthy mice $(n=3)$ serves as reference values: AST: $25.3 \pm 3.5 \mathrm{U} / \mathrm{L} ; \mathrm{ALT}: 33.3 \pm 2.1 \mathrm{U} / \mathrm{L} ; \mathrm{BUN}$ : $30.7 \pm 1.4 \mathrm{mg} / \mathrm{dL}$; Creatinine: $0.3 \pm 0.1 \mathrm{mg} / \mathrm{dL}$. *indicates $p<0.05$ versus vehicle or healthy group. 
methods or even the processing of KSY. Alternatively, possible synergistic or buffering interactions between these herbs may exist; thus, the pharmacological effects of KSY may be more complex and different from the effects of one single herb.

The inhibitory effects of KSY on cancer cells in vivo primarily resulted from the impairment of proliferation rather than the enhancement of apoptosis (Figures 4 and 5). Such growth-suppressive effects of KSY might be related to the increased expression of p53 and p21 (Figure 4). Both p53 and p21 are well-documented tumor suppressors and $\mathrm{p} 21$ is a known downstream gene of p53. The expression of p53 and p21 could be induced in response to various cellular stresses, leading to the downregulation of cyclin-dependent kinases to impair cell cycle progression [32]. Although the induction of p21 and p53 has also been reported to promote apoptosis of cancer cells [33,34], such correlation were not observed in the in vivo data (Figure 5). In line with the in vivo findings, direct treatment of bladder tumor cells with KSY led to cytostasis, in which both DNA synthesis and cell cycle progression were impaired (Figure 6). Based on aforementioned observation, growth suppression is the major anticancer effect of KSY, which was different from the immune-chemotherapeutic effects of OK432 [35] and the cytotoxic effects of Lipo-dox [36]. Multiple molecular mechanisms have been proposed to modulate the p53controlled target gene selection and cell fate determination [37]. It remains to be clarified whether KSY treatment triggers any of these regulatory mechanisms to specifically promote $\mathrm{p} 53$-dependent growth inhibition.

In clinical trial, KSY administration had been proven to improve quality of life and hepatic function in Hepatitis B inactive carriers without causing major adverse effects [9]. In this study, KSY treatment at a dosage comparable to that used in clinical study induced neither hepatic injury or nephrotoxicity in bladder or lung cancer mouse models whether combination with chemotherapy or not (Figures 7 and 8). Qi-promoting herbal medicine, such as KSY in this study, is traditionally considered to function as adjuvant for chemotherapeutic drugs $[38,39]$. Nevertheless, our data indicated that KSY did not enhance the therapeutic effect of chemotherapy drug doxorubicin (Figure 8). Since the combined treatment in our study was carried out in limited experimental conditions, the potential beneficial effects of KSY in combined with chemotherapy certainly merit further extensive investigation.

\section{Conclusions}

In this study, the anticancer potential and the safety of KSY were demonstrated, and the possible anticancer mechanism of KSY was through the suppression of cancer cell proliferation, instead of immunomodulation effects.
Until now, few studies have described the pharmacological activity of KSY, and this study is the first to reveal the potential tumor-suppressive effects of KSY using murine cancer models. In the future, more studies are warranted to further explore the therapeutic effect, action mechanism and herb-drug interactions of KSY with conventional cancer therapeutics.

\section{Additional files}

\section{Additional file 1: Supplemental method. \\ Additional file 2: Table S1. List of primers used for q-RT-PCR.}

Additional file 3: Figure S1. HPLC analysis of extracts from KSY and its constituted herbs.

Additional file 4: Figure S2. KSY treatment reduces BrdU-positive cells and interferes with cell cycle progression.

\section{Abbreviations}

KSY: Kuan-Sin-Yin; C3-B: C3H/HeN mice inoculated with MBT-2 cancer cells; Nu-B: BALB/CAnN-Foxn1nu/Cr1Nar1 mice inoculated with MBT-2 cancer cells; B6-L: C57BL/6 inoculated with LLC-1 lung cancer cells;

MTT: 3-(4,5-Dimethylthiazol-2-yl)-2,5-diphenyltetrazolium bromide; LPS: Lipopolysaccharide; PHA: Phytohemagglutinin; DAPI: 4',6-diamidino-2phenylindole; BrdU: 5-bromo-2'-deoxyuridine; ALT: Alanine aminotransferase; AST: Aspartate aminotransferase; BUN: Blood urea nitrogen.

\section{Competing interests}

The authors declare that they have no competing interests.

\section{Authors' contributions}

The study concepts were provided by $\mathrm{HCH}$ and $\mathrm{FSL}$, and experiments are designed by LTF and FSL. LTF, LCC and THP carried out the experiments and data collection. LTF and FSL also contributed to data evaluation, manuscript preparation, editing and review. $\mathrm{HCH}$ also participates in data analysis and interpretation together with LTF, LCC and FSL. All authors read and approved the final manuscript.

\section{Acknowledgments}

We are grateful for the technical support provided by Dr. Ting-Fen Tsai and Dr. Chun-Ming Chen. We also thank the Taiwan Mouse Clinic (NSC 102-2325B-001-042), which is funded by the National Research Program for Biopharmaceuticals (NRPB) at the National Science Council (NSC) of Taiwan, for technical support for the serum biochemistry analysis experiments. We also thank Wan-Chun Liu, Cheng Lin, and Lain-Tze Lee (Herbal Medicine Product Technology Division of the Biomedical Technology and Device Research Laboratories, Industrial Technology Research Institute) for the chemical profile analysis of KSY.

This study was supported by a grant from the Committee on Chinese Medicine and Pharmacy at the Department of Health, Executive Yuan, Taiwan (CCMP101-RD-016), a grant from the Taipei City Hospital (10001-62-008) and grants from Ministry of Science and Technology (MOST 103-2320-B-010-007-MY3; MOST 103-2320-B-010-009).

\section{Author details}

${ }^{1}$ Institute of Traditional Medicine, National Yang-Ming University, Taipei 11221, Taiwan. ${ }^{2}$ Herbal Medicine Product Technology Division of Biomedical Technology and Device Research Laboratories, Industrial Technology Research Institute, Hsinchu, Taiwan.

Received: 22 September 2014 Accepted: 11 December 2014 Published: 15 December 2014

\section{References}

1. Zhuang SR, Chen SL, Tsai JH, Huang CC, Wu TC, Liu WS, Tseng HC, Lee HS, Huang MC, Shane GT, Yang CH, Shen YC, Yan YY, Wang CK: Effect of citronellol and the Chinese medical herb complex on cellular immunity 
of cancer patients receiving chemotherapy/radiotherapy. Phytother Res 2009, 23(6):785-790.

2. Zitvogel L, Tesniere A, Apetoh L, Ghiringhelli F, Kroemer G: [Immunological aspects of anticancer chemotherapy]. Bull Acad Natl Med 2008, 192(7):1469-1487. discussion 1487-1489.

3. Anderson JG, Taylor AG: Use of complementary therapies for cancer symptom management: results of the 2007 National Health Interview Survey. J Altern Complement Med 2012, 18(3):235-241.

4. Verhoef MJ, Rose MS, White M, Balneaves LG: Declining conventional cancer treatment and using complementary and alternative medicine: a problem or a challenge? Curr Oncol 2008, 15(Suppl 2):s101-s106.

5. Konkimalla VB, Efferth T: Evidence-based Chinese medicine for cancer therapy. J Ethnopharmacol 2008, 116(2):207-210.

6. Mok TS, Yeo W, Johnson PJ, Hui P, Ho WM, Lam KC, Xu M, Chak K, Chan A, Wong H, Mo F, Zee B: A double-blind placebo-controlled randomized study of Chinese herbal medicine as complementary therapy for reduction of chemotherapy-induced toxicity. Ann Oncol 2007, 18(4):768-774.

7. McQuade JL, Meng Z, Chen Z, Wei Q, Zhang Y, Bei W, Palmer JL, Cohen L: Utilization of and attitudes towards traditional chinese medicine therapies in a chinese cancer hospital: a survey of patients and physicians. Evid Based Complement Alternat Med 2012, 2012:504507.

8. Chen FP, Chen TJ, Kung YY, Chen YC, Chou LF, Chen FJ, Hwang SJ: Use frequency of traditional Chinese medicine in Taiwan. BMC Health Serv Res 2007, 7:26.

9. Lee CJ, Cheng CH, Li YH, Liu CY, Hsu CH: A Chinese medicine, Kuan-Sin-Yin decoction, improves liver function in hepatitis $B$ virus carriers: a randomized, controlled study. J Altern Complement Med 2013, 19(12):964-969.

10. Chang $\mathrm{HH}$, Yeh $\mathrm{CH}$, Sheu $\mathrm{F}$ : A novel immunomodulatory protein from Poria cocos induces Toll-like receptor 4-dependent activation within mouse peritoneal macrophages. J Agric Food Chem 2009, 57(14):6129-6139.

11. Spelman K, Burns J, Nichols D, Winters N, Ottersberg S, Tenborg M: Modulation of cytokine expression by traditional medicines: a review of herbal immunomodulators. Altern Med Rev 2006, 11(2):128-150.

12. Chen $X$, Zhang $L$, Cheung PC: Immunopotentiation and anti-tumor activity of carboxymethylated-sulfated beta-( $1 \rightarrow 3)$-d-glucan from Poria cocos. Int Immunopharmacol 2010, 10(4):398-405.

13. Li J, Bao Y, Lam W, Li W, Lu F, Zhu X, Liu J, Wang H: Immunoregulatory and anti-tumor effects of polysaccharopeptide and Astragalus polysaccharides on tumor-bearing mice. Immunopharmacol Immunotoxicol 2008, 30(4):771-782.

14. Lin J, Dong HF, Oppenheim JJ, Howard OM: Effects of astragali radix on the growth of different cancer cell lines. World J Gastroenterol 2003, 9(4):670-673.

15. An HJ, Jeong HJ, Um JY, Park YJ, Park RK, Kim EC, Na HJ, Shin TY, Kim HM, Hong SH: Fructus Ligustrum lucidi inhibits inflammatory mediator release through inhibition of nuclear factor-kappaB in mouse peritoneal macrophages. J Pharm Pharmacol 2007, 59(9):1279-1285.

16. Jeong JC, Kim JW, Kwon CH, Kim TH, Kim YK: Fructus ligustri lucidi extracts induce human glioma cell death through regulation of Akt/mTOR pathway in vitro and reduce glioma tumor growth in U87MG xenograft mouse model. Phytother Res 2011, 25(3):429-434.

17. Sun YX: Immunological adjuvant effect of a water-soluble polysaccharide, CPP, from the roots of Codonopsis pilosula on the immune responses to ovalbumin in mice. Chem Biodivers 2009, 6(6):890-896.

18. Kang TH, Bang JY, Kim MH, Kang IC, Kim HM, Jeong HJ: Atractylenolide III, a sesquiterpenoid, induces apoptosis in human lung carcinoma A549 cells via mitochondria-mediated death pathway. Food Chem Toxicol 2011, 49(2):514-519.

19. Ye $Y$, Wang $H$, Chu JH, Chou GX, Chen SB, Mo H, Fong WF, Yu ZL: Atractylenolide II induces G1 cell-cycle arrest and apoptosis in B16 melanoma cells. J Ethnopharmacol 2011, 136(1):279-282.

20. He HL, Zhou XM, Wang Q, Zhao Y: Does the couse of astragaluscontaining chinese herbal prescriptions and radiotherapy benefit to non-small-cell lung cancer treatment: a meta-analysis of randomized trials. Evid-Based Complent Alt Med 2013, 2013:426207.

21. Guo L, Bai SP, Zhao L, Wang XH: Astragalus polysaccharide injection integrated with vinorelbine and cisplatin for patients with advanced non-small cell lung cancer: effects on quality of life and survival. Med Oncol 2012, 29(3):1656-1662.
22. Zhuang SR, Chiu HF, Chen SL, Tsai JH, Lee MY, Lee HS, Shen YC, Yan YY, Shane GT, Wang CK: Effects of a Chinese medical herbs complex on cellular immunity and toxicity-related conditions of breast cancer patients. Br J Nutr 2012, 107(5):712-718.

23. Liao HF, Chen YJ, Yang YC: A novel polysaccharide of black soybean promotes myelopoiesis and reconstitutes bone marrow after 5-flurouracil- and irradiation-induced myelosuppression. Life Sci 2005, 77(4):400-413.

24. Lin YS, Huang LD, Lin CH, Huang PH, Chen YJ, Wong FH, Lin CC, Fu SL: In vitro and in vivo anticancer activity of a synthetic glycolipid as Toll-like receptor 4 (TLR4) activator. J Biol Chem 2011, 286(51):43782-43792.

25. Hung LC, Lin CC, Hung SK, Wu BC, Jan MD, Liou SH, Fu SL: A synthetic analog of alpha-galactosylceramide induces macrophage activation via the TLR4-signaling pathways. Biochem Pharmacol 2007, 73(12):1957-1970.

26. Hung SK, Hung LC, Kuo CD, Lee KY, Lee MS, Lin HY, Chen YJ, Fu SL: Andrographolide sensitizes Ras-transformed cells to radiation in vitro and in vivo. Int J Radiat Oncol Biol Phys 2010, 77(4):1232-1239.

27. Reagan-Shaw S, Nihal M, Ahmad N: Dose translation from animal to human studies revisited. FASEB J 2008, 22(3):659-661.

28. Mouse phenome database. [http://phenome.jax.org/]

29. Zamarron BF, Chen W: Dual roles of immune cells and their factors in cancer development and progression. Int J Biol Sci 2011, 7(5):651-658.

30. Liu JJ, Huang TS, Hsu ML, Chen CC, Lin WS, Lu FJ, Chang WH: Antitumor effects of the partially purified polysaccharides from Antrodia camphorata and the mechanism of its action. Toxicol Appl Pharmacol 2004, 201(2):186-193.

31. Lu H, Yang Y, Gad E, Wenner CA, Chang A, Larson ER, Dang Y, Martzen M, Standish L, Disis ML: Polysaccharide krestin is a novel TLR2 agonist that mediates inhibition of tumor growth via stimulation of CD8 T cells and NK cells. Clin Cancer Res 2011, 17(1):67-76.

32. Wang Z, Sun $Y$ : Targeting p53 for novel anticancer therapy. Trans/ Oncol 2010, 3(1):1-12.

33. Li TM, Chen GW, Su CC, Lin JG, Yeh CC, Cheng KC, Chung JG: Ellagic acid induced p53/p21 expression, G1 arrest and apoptosis in human bladder cancer T24 cells. Anticancer Res 2005, 25(2A):971-979.

34. Kuang YF, Chen YH: Induction of apoptosis in a non-small cell human lung cancer cell line by isothiocyanates is associated with P53 and P21. Food Chem Toxicol 2004, 42(10):1711-1718.

35. Ryoma Y, Moriya Y, Okamoto M, Kanaya I, Saito M, Sato M: Biological effect of OK-432 (picibanil) and possible application to dendritic cell therapy. Anticancer Res 2004, 24(5C):3295-3301

36. Minotti G, Menna P, Salvatorelli E, Cairo G, Gianni L: Anthracyclines: molecular advances and pharmacologic developments in antitumor activity and cardiotoxicity. Pharmacol Rev 2004, 56(2):185-229.

37. Carvajal LA, Manfredi Jj: Another fork in the road-life or death decisions by the tumour suppressor p53. EMBO Rep 2013, 14(5):414-421.

38. Chen S, Flower A, Ritchie A, Liu J, Molassiotis A, Yu H, Lewith G: Oral Chinese herbal medicine ( $\mathrm{CHM})$ as an adjuvant treatment during chemotherapy for non-small cell lung cancer: a systematic review. Lung Cancer 2010, 68(2):137-145

39. Zhong LL, Chen HY, Cho WC, Meng XM, Tong Y: The efficacy of Chinese herbal medicine as an adjunctive therapy for colorectal cancer: $a$ systematic review and meta-analysis. Complement Ther Med 2012, 20(4):240-252

\section{doi:10.1186/1472-6882-14-488}

Cite this article as: Li et al:: Effects of Kuan-Sin-Yin decoction on immunomodulation and tumorigenesis in mouse tumor models. BMC Complementary and Alternative Medicine 2014 14:488. 